\title{
Role of Iraqi Higher Education Institutes in Handling National/International Environmental and Health Challenges
}

\author{
Salam J. Bash Al-Maliky ${ }^{1}$ \\ ${ }^{1}$ Associate Professor, Environmental Engineering, Al-Mustansiriya University, Iraq \\ Correspondence: Salam J. Bash Al-Maliky, Associate Professor, Environmental Engineering, Al-Mustansiriya \\ University, Iraq. E-mail: Salambash2000@yahoo.com; bashs@ohio.edu
}

Received: June 5, 2012 Accepted: July 2, 2012 Online Published: August 22, 2012

doi:10.5539/hes.v2n3p110

URL: http://dx.doi.org/10.5539/hes.v2n3p110

\begin{abstract}
Huge environmental and health crises such as the use of Depleted Uranium (DU) munitions during the military activities against Iraq and the required responses are amongst the fields that Iraqi higher education institutions (HEIs) may have a crucial role. Similar international cases, such as Agent Orange (Vietnam), Three Mile Island (USA) and Chernobyl (Ukraine) were discussed, pointing out the consequences of participation/non participation of such institutions. Liberation of academic and research curriculums and programs from the strict controls of governmental authorities, and general modernization campaign for courses offered by the relevant institutions were found essential to define and meet the modern challenges and changes, via the adoption of national/international interaction and expertise exchange with similar institutes. An effective communication and information sharing system would be an important corner stone in any mutual cooperative effort; either inside HEIs community or between them and the relevant entities.
\end{abstract}

Keywords: communication, depleted uranium, environmental problem, higher education reform, Iraq

\section{Introduction}

One essential role of the higher education institutes was to develop educational systems to respond to national/international environmental and health challenges on systematic, professional and timely manners. This may involve, but not limited to, preparing students to comprehend, analyze and manage practical cases based on local, regional and global systematic variables. General national strategy should be well planned within the educational system, for such actions that integrate the required stability between realistic and theoretical knowledge. Such strategy may be based on the past environmental crises and their evident effects and proximity of future possibilities in order to priorities educational needs (Ziegler 2009). While for the Republic of Belarus, the essential educational spotlight, was the important ecological problems involved with the consequences of the Chernobyl explosion, 1986, when more than $22 \%$ of the country was covered by radioactive pollution (Goncharova 2009), the educational approach that was expressed by many US universities had stipulate the ethics that oblige their students to achieve balanced process between high production from one side and the environmental components from the other one (Gundersen and O'Day, 2009).

The organizational members of the HEI (Faculty, students, administrators, and so on) are quite different as compared to other institutions in the sense that in addition to the understandings of their own organization, they have their joint projects towards bridging gaps and developments of the larger world. Hence, a fluent and efficient information exchange (communication) system is crucial for such mission to be accomplished. Distances were no more an obstacle against data transmission in the current world that relies on huge information exchange and communication means and consequently, time was so shorter to handle key changes in concepts of education, economic, social, and political issues that were raised thereafter.

The goal of this study was to study of the international practices and responses through HEIs of three nations against modern national/international environmental and health challenges that directly affect the lives, resources and interests of public, in order to extract best lessons and make implications that may enhance the status of Iraqi HEIs. The use of DU munitions against Iraq during the first and second gulf wars 1991 and 2003 respectively, was selected for as one of the biggest environmental contributory for major negative alterations of the regional environment during the last decades. 


\subsection{Background: Iraq Higher Education Institutes}

Since their creation at early 1920s Iraqi academic institutions were controlled by firmly centralized dimensions. Numbers of students each institute may enroll was a decision to be made by the central government, in addition to the allocation of students regarding study fields, and the salaries university instructors were paid (in the case of public universities). Core decisions to the operations of academic institutions such as hiring faculty were controlled by the center. Incentive for universities and institutes to compete or innovate was denied by such kind of system. Payment role was based on seniority, and although current official salaries are significantly greater compared with the case prior to 2003 when university instructors were in every day excessive struggle to support themselves, it is still the case that higher education institutes of Iraq do not yet offer incentives to foreign educated/resident Iraqis to resettle in Iraq.

Iraqi HEIs were regionally and internationally remarkable prior to the 1980 s of the past century in the degree that their faculty and graduates were highly demanded to teach or work at similar or relevant institutes of these countries. Afterward, these institutes lacked intellectual dynamism due to corruption and the intrusion of political manipulation. A web of formal and informal controls and constraints were pursuing since then, even as universities have progressively been accorded wider space, to ensure that HEI remain intellectually dilapidated while regional counterparts were gradually improving.

For much of the period post to 2003 when Iraq was in process to reform its economic and political structure towards liberalization and democracy, the rate of reform in higher education has not been satisfactory for the most observers. Majority of academics believe that the quality of courses and administrative structure that are still adopting out of date references and instructions, has declined due to the non-clarity of the new status; central or provincial based.

The implementation of the modifications on Higher education service law 23 of 2008 was a higher priority to education reform and was a time for the government to implement reforms, including better enhancement for the faculty and staff salaries. Although it was not easy to measure that law's influence on the education progression, yet the change rate remained slow as long as it still contains some controversial issues regarding the authorities and duties.

Iraqi environment has suffered many problems for decades, such as the Nile flower that led to many clogs in surface water resources; e.g. rivers Dijlah and Forat, in addition to the consumption of huge amounts of water. Another problem was the desertification and consequent dust storms that attacked big cities due to the absence of reliable plantation and irrigation strategies. Surface water pollution due to the industrial spills has been one of the important hazards especially when involved with the discharges of hospitals, medical and radiological laboratories, petrochemical industries and so on, as these hazardous spills may find their ways to main drinking or irrigation systems due to the insufficient treatment processes. Also, the increased numbers of vehicles (majority were old ones) and the deteriorated quality of fuel had created many air pollution problems in big cities like Baghdad where the increase of Lead concentrations was of high concern for the relevant entities.

prior to 2003, strict ban was imposed by higher governmental authorities against the participations of almost all HEIs in real studies regarding the previously mentioned environmental problems, to the extent that the ex-dictator of Iraq (those times) has announced that Iraqi environment was clean of any type of pollution (TV announcement 1996) which was translated as: prohibit such studies but for specific entities, the results of which were considered as highly classified. After 2003, and with the stockpile of all types of problems; political, security, economic, administrative and so on, the resources to held serious national studies were so limited for the majority of Iraqi HEIs that were sinking in an overwhelming reconstruction process on all aspects.

\section{Case Study: Use of Depleted Uranium (DU) Munitions against Iraq}

Since DU was first used in Iraq, it has become an international and controversial issue facing environmental risks versus military use. Occupying troops in Iraq had used about 2,000 tons of DU during the second gulf war of 2003 (in addition to more than 350 tons during the first gulf war of 1991), hence the US and UK use of toxic weapons was declared by many human rights organizations as a crime against humanity based on indications that over 140,000 cases of cancer in contaminated areas throughout the country have been reported, leading (Dixon, 2003). DU is the byproduct of the process during which fissionable U-235 used for nuclear reactors and nuclear weapons is separated from natural uranium. The very long half life of DU (about 4.5 billion years) makes radioactive forever and is very suitable for military technology because it is extremely dense and heavy; about 1.7 as density of Lead (Miller 2007), such that munitions with DU heads can penetrate the armored shields of military vehicles and buildings. In addition, DU weapons are more effective bio- weapons as its chemical affinity for phosphate structures is strongly concentrated in DNA. Under the right conditions, one alpha particle 
may start Cancer, and 12,000 alpha particles per second are released by only one gram of DU.

\subsection{Stance of Iraq}

Iraqi government has a similar stance to the US, on the DU issue since the later has the funds, resources and equipments to assess the effects of DU exposure and have reported that they have not found a direct connection in the concern for health risks. It was very difficult for the Iraqi government, Ministry of Health, and in turn, the Ministry and institutes of higher education to develop and maintain such kind of studies. In turn it gives complex political, security and technical stockpile of problems against individuals and advocacy groups who seek to study or remediate this huge unclear crisis.

It was difficult to provide an accurate statistic for the number of civilian casualties and cases of DU caused health ailments from the war in Iraq, due to the lack of government cooperation and assistance in the matter, to the extent that the chief Iraq Ministry of Health statistician was ordered to stop counting civilian war deaths in 2003, while a survey conducted by Medact (global health charity) has estimated in 2004 that the invasion and occupation of Iraq resulted in a death toll of about 100,000 civilians as a modest estimate (Salvage 2007). The likelihood that the number of deaths will continue to increase due to DU related illnesses is high, especially when taking into account the state of the current public health infrastructure and lack of government acknowledgement of the issue. These predictions were highly emphasized by the various alerts of increase in cancer cases at Al-Fohod county of Nasiriya, about $365 \mathrm{Km}$ south of Baghdad and Maysan, about $375 \mathrm{Km}$ south of Baghdad close to the boarders with Iran (EINa'eb, 2007), Faluja, about $68 \mathrm{Km}$ north west of Baghdad (Busby, Hamdan and Ariabi 2010) and other regions whom no specific records were published on their regard. Despite the fact that the Ministry of Health keeps deny these figures, but still no published records support these denials.

Although, authors have surveyed more than 50 Iraqi and Arab websites, newspapers and media channels (ntlworld.com, alsabaah.com, middle-east-online.com, cleaniraq.org, almadapaper.net, hurights.org, aljazeera.net, and so on) that announced many activities; presentations, workshops, studies and surveillances, held by various Iraqi HEIs to explain, warn, or suggest solutions about the DU issue (one of these presentations was made by the authors at the college of Engineering, May, 2009), no documented scientific papers or data could have been retrieved from these activities due to many reasons such as, but not limited to, the lack of credible communication, coordination and data basing means and lack of applicable legislative enforcement rules that control this process.

\subsection{International Comparative Cases}

\subsubsection{Case one: Agent Orange, Vietnam}

Vietnam was subject to an aerial bombardment during the 1960s that was three to four times greater than the Second World War total tonnage release. However, the greatest long-term negative impact on the country and its people was due to the use of chemical defoliants to remove the lush and forests in the south and center areas in order for the US military to better target the Vietnamese resistance. The greatest long term consequences were resulted from the combination trees and vegetation killing by napalm bombardment that was followed by burning them with Agent Orange, and ending with the final removal via bulldozers. About 1.4 billion hectares of land and forest that counts for about $12 \%$ of Vietnam's total land area were sprayed with 80 million liters of this chemical between 1962 and 1970, resulting the expose of 2.5 to 4.8 million people to the lethal effects of an essential component of Agent Orange that was called as "Dioxin" (National Organization on Disability, 2009). Furthermore, the underground burial of many barrels of dioxin had led to several accidental spillages such as that one which caused the seepage of 22,000 liters of Agent Orange into a lake beside Bien Hoa town, home to 20,000 people.

After the war ended, Vietnam's main focus was on rebuilding the country and establishing safety and security. Thus, few initial cleanup efforts were made, as the country was too busy rebuilding its infrastructure and society to even begin to see the extent of Agent Orange's presence and toxicity within Vietnam. As HEI were highly centralized and allied to the governmental policies, they had neither freedom nor resources to research the Agent Orange problem (Vallely and Wilkinson 2008). As awareness of the issue grew, Vietnam stabilized, and normal diplomatic relations between the US and Vietnam returned in 1995, efforts of Agent Orange revision and remediation began to rise on the top of international precedence list for different relevant entities including HEIs (although about 30 years late) and considerable evolution was beginning to be achieved (Ford Foundation 2011).

\subsubsection{Case Two: Three Mile Island (TMI), USA}

On March, 1979 the Three Mile Island (TMI) Accident occurred in Middletown, Pennsylvania, USA. The most serious commercial nuclear power plant accident in U.S history happened after a mechanical or electrical failure that caused the meltdown of around one-half of the core. 
According to Dunstan, 2002 "Cancer, leukemia, birth defects, stillbirths, malformations, spontaneous abortions, skin lesions, hair loss, respiratory problems, sterility, nausea, cataracts, a metallic taste, premature aging, general loss of bodily function and more can be caused by radioactive emissions of the type that poured out of TMI". None of the TMI administrative reporters has covered the presentations of neither Dr. Wing, University of North Carolina`s epidemiologist, nuclear engineer Gundersen, nor the paper of Dr. Sternglass the radiology professor emeritus of University of Pittsburgh and Mangano and Gould the health researchers whom all announced solid evidences regarding the dangerous potential health crisis (Wasserman 2009).

Educational institutes, media, websites and environmental groups have announced many proofs regarding the swell of death toll that was linked to TMI death; e.g. Institute for Public Accuracy, the Pacifica and Counter spin/Fair radio networks, WORT (Madison), KBOO (Oregon), KDKA (Pittsburgh), Huffington Post, FreePress.org, Nuke Free, Greenpeace, NIRS and many others (Dickinson College 2007), that supported the filing process of federal class action lawsuit for 2400 Pennsylvania families in order to claim damages from the accident, and enabled citizens' groups to win a class action suit against TMI with $\$ 25 \mathrm{M}$ in an out-of-court settlement (Greene 2001).

\subsubsection{Case three: Chernobyl, Ukraine}

On 26 April 1986, the water coolant vaporized in reactor-4 following a complex events chain at the Chernobyl plant, resulting in an explosion that would destroy the reactor (Rosenthal 2005). Plumes of radioactive material were dispersed through the atmosphere over a wide geographical area and the plant caught fire. The plant blew more than 20 million curies of radioactive material and several million curies of the inert radioactive gases, Xe-I33 and Kr-85, into the atmosphere (Warren 1997). About 16,500 police and firemen were sent to help control the fire and clean up contamination in the aftermath, many of them who stayed at the power plant for 10-12 hours wore no protective gear; they were unaware of the harm of radioactive exposure, hence, 57 suffered acute radioactive sickness, 1500 developed chronic respiratory or digestive problems and more than 4000 showed other symptoms. Furthermore, a huge cleanup operation involving 240,000 workers was implemented over the next four years, with fears that many of these workers "liquidators," would suffer in subsequent years (Eisenberg 2001).

The Soviet government's first reaction was to cover this information, but when certain evidences were revealed these officials were forced to declare the accident, and the release of radioactive plumes that broaden over the country and across Europe. Charges of some Soviet politicians and scientists had claimed that at least 20 times more radiation the reactor released compared to what the government has admitted, and the instant evacuation campaign for the nearby towns and cities was failed, even though the communist officials were aware of the danger (Yablokov, Nesterenko, Nesterenko, and Sherman-Nevinger 2010).

The platform of International communications on the long term consequences of the Chernobyl disaster (UN General Assembly, 2005), had indicated that about 4000 cases of thyroid cancer were diagnosed among those who were children and adolescents (0-18 years) at the time of the accident between 1992-2000 in Belarus, Russia and Ukraine, which represented 30 times the cases prior to the accident. In the Northern Hemisphere, about 550 million Europeans and others 150 to 230 million received notable contamination. Nine days after the disaster, fallout reached the United States and Canada (Yablokov, Nesterenko, and Nesterenko, 2009).

\section{Iraqi HEIs: Implications for the Contemporary Context}

According to the above discussion, the major factors to determine the readiness of Iraqi HEIs for positive responses against current and future environmental and health challenges were summarized by the following:

1) Study goals and strategies;

2) IT skills and resources (particularly software applications and computer hardware);

3) Communication skills and resources (Journals, newspapers, phone, fax, Internet and so on); and

4) English language acquisition (faculty and students).

The HEIs of Iraq needs documented and legitimate sound policies and strategies, obvious vision, an applicable regulatory framework to endorse autonomy and liability towards road mapping the gap with regional and international standards in access, significance, quality, attractiveness, and competitiveness.

One crucial motivation for the Iraqi HEIs to cope with the past, recent and future challenges and play a positive role on these regards is to liberate them from the strict governmental laws and instructions that limit their capacity to search topics that may not be approved under general or special governmental policies. However, this liberation process should not be radical or short term process, as this kind of actions may jeopardize the whole 
system due to the lack of experience and enforcement bodies, and rather transitional measures would be more effective with the adoption of a regional model application to exert some lessons for the long term national HEIs liberation process.

another essential step towards the reform of HEIs in Iraq would be the adoption of general modernization campaign for courses offered by the relevant institutions so as to meet the modern challenges and changes, and a corner stone on that regard would be the adoption of national/international interaction and expertise exchange with similar institutes on all levels; e.g. administrative, technical, academic (undergraduate and graduate studies) and human resources. Such campaigns should be based on thorough revisions and readings of past planes, current and future anticipations of environmental status and changes, and the available and expected resources.

The development and maintenance of an effective modern communication and information sharing system that links the various HEIs together and links them with the relevant governmental and nongovernmental offices and entities, would be an important tool in any mutual cooperative effort, in addition to the necessity to create functional websites for these different HEIs or maintain the current ones to play both informative and processing roles, as the case with the counterparts all over the developed world.

In addition to the urgent need for the relevant modern hardware and software for the majority of these institutions, huge campaigns are highly recommended to cruet qualified personnel, and train the available staff (both teaching and administrative ones), on the use of modern communication systems. In this regard, NGOs and International Communities have been proven as great resources for comparative cases to the Iraqi HEIs (logistic, funding, media and other experiences).

It is highly recommended to re-initiate the technical English language courses for the first year students (at least) in order to prepare them to handle their courses with more effective and professional manner. Also, the encouragement and well coordination for these students to attained and/or participate the various seminars, workshops, graduate students defense sessions as compulsory requirement for their grading, as the case with many highly recognized international Universities would be a good incentive on that regard.

Finally the establish (or re-activate, if already exist) and maintain of certain units that are responsible on the coordination, monitoring, and developing all kinds of technical communications and knowledge exchange inside the HEIs community and with the relevant outside entities would be great enhancement for the HEIs to respond to modern changes and challenges on timely and effective manners. Such units may assume the task of follow up, or access of up to date technical papers or documents and make them accessible for students and faculty.

\section{Conclusions}

The roles of management, communication, modernization and training was studied for the HEIs in order to respond to environmental and health crises that may affect current and future generations. Three international catastrophes; Agent Orange (Vietnam), TMI (USA), and Chernobyl (Ukraine), were analyzed for their regional HEIs resources and actions to handle their consequences. Many lessons may be excreted from the international case studies that can promote the handle of big environmental and health crises and the way Iraqi HEIs may take part on that. The Vietnamese's case of Agent Orange problem was very clear evidence that late address and announcement of such crises would lead to higher causalities and may incorporate some long term consequences that often makes it even harder to remediate. Also paralyzed or resource-less HEIs would have no significant outcome in addressing, evaluating or remediating such problems, while well prepared ones would play a significant role in such tasks on both timely and economic manners; as the case with the American Universities during the period after TMI accident, compared to the status of Vietnam's HEIs versus Agent Orange catastrophe. Another crucial lesson from the TMI accident was that educational institutes and all major media outlets should train specialist in the topic they cover in order to avoid public chaos and to reveal relevant correct information on precise and timely manners. Finally, it was noticed from the case of Chernobyl accident that the intrusion of politics and governmental occasional and/or long term interests in such crises would play a very harmful role in delaying the positive response of relevant entities such as HEIs, for the benefit of current and future generations and environment on both national and international scales.

\section{References}

Alexandra, M. C. (2007). Depleted Uranium: Properties, Uses, and Health Consequences. Boca Raton: CRC Press, Taylor and Francis Group. http://dx.doi.org/10.1201/9781420004564.fmatt

Busby, C., Hamdan, M., \& Ariabi, E. (2010). Cancer, Infant Mortality and Birth Sex-Ratio in Fallujah, Iraq 2005-2009. International Journal of Environmental Research and Public Health, 7(7), 2828-2837. http://dx.doi.org/10.3390/ijerph7072828 
Dickenson College. (2007). Three Mile Island emergency. Retrieved August 29, 2009 from $\mathrm{http}: / /$ www.threemileisland.org/about.htm

Dixon, M., \& Fitz-Gibbon, S. (2003). The Environmental Consequences of the War on Iraq. Retrieved December, 2011 from http://www.greenparty.org.uk/

Dunstan, R. (2002). Benefits and Risks of Nuclear Power in California. Sacramento, CA: California Research Bureau, California State Library.

Eisenberg, J. M. (2001). Putting research to work: Reporting and enhancing the impact of health services research. Health Services Research, 36(2), x-xvii.

ElNa 'eb M.Am. (2007). Radiation Pollution in Iraq and it future consequences. Journal of Environment and life, 17.

Ford Foundation. (2011). Environmental and human health assessment of Dioxin contamination at Bien Hoa airbase, Vietnam. $\quad$ Retrieved January, 2012 from http://www.skysoldiers.com/BienHoaFinalSummaryReport_August2011\%20resize.pdf.

Goncharova, N. (2009). Environmental security and the role of UNESCO chairs in higher education in Belarus. In S. Allen-Gil, L. Stelljes, \& O. Borysova (Eds.), Addressing Global Environmental Security through Innovative Educational Curricula. Dordrecht, Netherlands: Springer. http://dx.doi.org/10.1007/978-1-4020-9314-2_3

Greene, G. (2001). The woman who knew too much: Alice Stewart and the Secrets of Radiation. Michigan: University of Michigan Press.

Gunderson, D. T., \& O'Day, T. (2009). Permaculture, a natural systems design approach for teaching sustainability in higher education: Pacific University's B-Street permaculture project. In S. Allen-Gil, L. Stelljes, \& O. Borysova (Eds.), Addressing Global Environmental Security through Innovative Educational Curricula. Dordrecht, Netherlands: Springer. http://dx.doi.org/10.1007/978-1-4020-9314-2_16

Jackson, M. H., \& McDawell, S. D. (2000). Enhancing discourse on new technology within higher education. Information, Communication and Society, 3(4), 629-638. http://dx.doi.org/10.1080/13691180010002125

National Organization on Disability. (2009). U. S. Vietnam Veterans and Agent Orange: Understanding the Impact 40 Years Later. Retrieved January, 2012 from http://www.warlegacies.org/VeteransandAO.pdf

Rosenthal, E. (2005). Experts find reduced effects of Chernobyl. Retrieved January, 2012 from http://www.nytimes.com/2005/09/06/international/europe/06chernobyl.html?_r=1\&pagewanted=all.

Salvage J. (2007). Politics of evidence: Conflict and health in Iraq. International Journal of Evidence-Based Healthcare, 5(2), 261-265. http://dx.doi.org/10.1111/j.1479-6988.2007.00067.x

UN General Assembly. (2005). Optimizing the international effort to study, mitigate and minimize the consequences of the Chernobyl disaster. Retrieved December, 2011 from $\mathrm{http}: / /$ chernobyl.undp.org/russian/docs/a_60_443_e.pdf

Vallely, T. J., \& Wilkinson, B. (2008). Vietnamese Higher Education: Crisis and Response. Retrieved December, 2011 from http://www.hks.harvard.edu/innovations/asia/Documents/HigherEducationOverview112008.pdf

Warren, P. (1997). Hazardous gases and fumes, a safety handbook. Oxford, UK: Butterworth-Heinemann.

Wasserman, H. (2009). People died at Three Mile Island. Killing our own: The disaster of America's experience with atomic radiation. New York: Dell Publishing Co., Inc.

Yablokov, A. V., Nesterenko, V. B., Nesterenko A. V., \& Sherman-Nevinger, J. D. (2009). Chernobyl: Consequences of the Catastrophe for People and the Environment. Annals of the New York academy of science, 1181. New York: The New York Academy of Sciences.

Ziegler R. (2009). Science on the marsh: Towards the ground of education (for sustainable development). In S. Allen-Gil, L. Stelljes, \& O. Borysova (Eds.), Addressing Global Environmental Security through Innovative Educational Curricula. Dordrecht, Netherlands: Springer. http://dx.doi.org/10.1007/978-1-4020-9314-2_2 